\title{
Molecular Analysis of Sleep
}

\author{
M. TAFTI AND P. FRANKEN \\ Center for Integrative Genomics, University of Lausanne, 1015 Lausanne, Switzerland
}

\begin{abstract}
Rest or sleep in all animal species constitutes a period of quiescence necessary for recovery from activity. Whether rest and activity observed in all organisms share a similar fundamental molecular basis with sleep and wakefulness in mammals has not yet been established. In addition and in contrast to the circadian system, strong evidence that sleep is regulated at the transcriptional level is lacking. Nevertheless, several studies indicate that single genes may regulate some specific aspects of sleep. Efforts to better understand or confirm the role of known neurotransmission pathways in sleep-wake regulation using transgenic approaches resulted so far in only limited new insights. Recent gene expression profiling efforts in rats, mice, and fruit flies are promising and suggest that only a few gene categories are differentially regulated by behavioral state. How molecular analysis can help us to understand sleep is the focus of this chapter.
\end{abstract}

\section{INTRODUCTION}

Wakefulness, nonrapid eye movement (NREM), and rapid-eye movement (REM) sleep constitute the three states of vigilance in mammals and birds as defined by changes in brain electrical activity measured by the electroencephalogram (EEG), in muscle tone by the electromyogram $(\mathrm{EMG})$, and in eye movements by the electro-oculogram (EOG). The EEG measures mainly cortical activity, and in species without a cortex or an underdeveloped cortex, changes in the EEG do not necessarily correlate with behavior. In addition, eye movements are absent in some species and muscle tone may not change in others, making these basic electrophysiological measures applicable only in mammals and birds. Other behavioral correlates of sleep must thus be used in most other species, including immobility, a stereotypic posture, reduced reactivity to external stimuli, reversibility to the waking state, and, of major importance, homeostatic regulation. Homeostatic regulation implies that the amount (or intensity) of rest should be correlated with that of the preceding duration of activity and therefore rest deprivation should result in a subsequent increase or rebound in rest (Campbell and Tobler 1984). These criteria can be applied to rest in many species, suggesting that sleep in mammals and birds shares some basic features with rest in species where sleep cannot be defined using the EEG and EMG. Sleep, as other behaviors, is also under the control of a circadian process that regulates its appropriate timing and structure. Lesions of the suprachiasmatic nucleus ( $\mathrm{SCN})$, the master clock in mammals, result in arrhythmic sleep and wakefulness, although the homeostatic response to sleep deprivation remains unchanged (Trachsel et al. 1992). However, recent evidence indicates a close relationship at the molecular level between the circadian and homeostatic processes regulating sleep (see Franken et al. 2007).

As early as the 1950s, twin studies in humans suggested that the amount and the structure of sleep are controlled by genetic factors (for review, see Dauvilliers et al. 2005; Tafti et al. 2005). More recent studies in inbred mice confirmed that not only the amount and the organization of sleep, but also specific features of the sleep EEG are under strong genetic control (Tafti et al. 1999; Tafti and Franken 2002). More specifically, single genes have been identified that affect EEG $\theta$ frequency $(5-8 \mathrm{~Hz})$ characteristic of REM sleep and $\delta(1-4 \mathrm{~Hz})$ EEG activity characteristic of NREM sleep (Tafti et al. 2003; Maret et al. 2005). Molecular genetics of sleep disorders also made substantial progress recently with the identification of the genetic bases of fatal familial insomnia, narcolepsy, familial advanced sleep phase syndrome (FAPS), and restless legs and periodic limb movements in sleep (Stefansson et al. 2007; Tafti et al. 2007; Winkelmann et al. 2007). Nevertheless, the molecular bases of normal sleep and its regulation remain poorly understood. As summarized below, the endeavor is rendered difficult by the highly complex mechanisms underlying sleep regulation.

\section{MOLECULAR NEUROCHEMISTRY OF SLEEP}

Lesion and pharmacological studies show that sleep and wakefulness are controlled by multiple neuronal systems using different chemical neurotransmitters such as glutamate, acetylcholine, noradrenalin, dopamine, serotonin, histamine, adenosine, $\gamma$-amino- $n$-butyric acid (GABA), and orexin (Saper et al. 2005). Many of the neurons that are part of these control systems have widespread, direct, or diffuse projections to the cortex, subcortical relays, and brain stem or spinal cord, thus enabling them to influence the general state of arousal. Here, we give a brief overview of the results obtained in transgenic mouse models that were used to further elucidate the role of these signaling pathways in sleep.

The first neurotransmitter system that has been involved in sleep is serotonin. Serotonin neurons are active during wakefulness, diminish their activity during NREM, and are inactive during REM sleep. Sleep analyses in different serotonergic loss-of-function models indicated that the deletion of 5-HT1B and 5-HT1A receptors or the 5-HT transporter results in an increased amount of REM sleep (Boutrel et al. 1999, 2002; Wisor et al. 2003) 
without major effects on other aspects of sleep, confirming a selective role of the serotonergic system in the control of REM sleep.

The noradrenergic neurons of the locus coeruleus change activity very similar to that of serotonergic neurons and are critically involved in initiating and maintaining wakefulness, attention, and many other waking-related higher brain functions. Although pharmacological data have long implicated the noradrenergic system in the control of REM sleep, conflicting results have been reported with noradrenalin-deficient transgenic mice in which the dopamine $\beta$-hydroxylase gene was deleted (Hunsley and Palmiter 2003; Ouyang et al. 2004). The first study reported no major changes in sleep (Hunsley and Palmiter 2003), whereas the second reported a 2-hour reduction in time spent awake and a twofold reduction in REM sleep duration in mutant mice as compared to wild-type controls (Ouyang et al. 2004).

The role of dopamine is less well understood, but the deletion of the dopamine transporter decreased NREM sleep and increased wakefulness in mice (Wisor et al. 2001). Also in the fruit fly, the lack of the dopamine transporter resulted in decreased sleep time and increased wakefulness (Kume et al. 2005), strongly suggesting that dopamine is critically involved in the promotion and maintenance of wakefulness.

The cholinergic system is involved in wakefulness and REM sleep, but little molecular data are available to demonstrate its role in vigilance states. Mice lacking the $\beta_{2}$ subunit gene of the nicotinic acetycholine receptors show no change in any aspects of sleep, except for a slightly more consolidated REM sleep (Lena et al. 2004). The implication of the cholinergic system in REM sleep regulation is pharmacologically mediated through muscarinic receptors, and loss of function of many muscarinic receptors leads to hyperactivity, most probably due to increased dopaminergic tone (Wess 2004), but whether or not REM sleep is modified in these mice is unknown.

The role of histaminergic and adenosinergic systems in sleep has become increasingly recognized (McCarley 2007; Parmentier et al. 2007). Histaminergic neurons are selectively active during wakefulness and silent during sleep. Mice lacking the histidine decarboxylase gene that cannot synthesize histamine have increased REM sleep and seem to be hypersomnolent (Parmentier et al. 2002). Histamine H1 receptor knockout mice have consolidated sleep and do not react to the arousing effects of H3 receptor agonists (Huang et al. 2006), confirming the general interest in antihistaminergic drugs to promote sleep and H3 receptor agonists as stimulants (Parmentier et al. 2007). Adenosine is thought to induce and increase sleep in specific brain regions such as the basal forebrain and the ventral lateral preoptic area. However, whether adenosine acts at specific brain regions and through different receptors (A1 or A2a) or globally is a matter of debate (BlancoCenturion et al. 2006; Noor Alam et al. 2006). Nevertheless, mice with $\mathrm{A} 2 \mathrm{a}$ receptor loss of function have reduced sleep and reduced response to sleep deprivation and caffeine (Urade et al. 2003; Huang et al. 2005). In addition, in humans, genetic variations in adenosine deaminase and $\mathrm{A} 2 \mathrm{a}$ receptors affect sleep duration and intensity
(Retey et al. 2005) and sensitivity to caffeine (Retey et al. 2007), corroborating the findings in mouse models.

The neurotransmitters orexin and melanin-concentrating hormone $(\mathrm{MCH})$ have been recently involved in sleep regulation (Modirrousta et al. 2005). Deletion of the orexin gene or orexin neurons results in a phenotype similar to human and canine narcolepsy with cataplexy (i.e., loss of muscle tone triggered by strong emotions) and abrupt transition from wakefulness to REM sleep (Chemelli et al. 1999; Hara et al. 2001). In addition, orexin receptor-2 mutations in dogs (Lin et al. 1999) and KO mice have narcolepsy-like symptoms, although receptor-2-deficient mice are less severely affected than ligand-deficient mice (Willie et al. 2003).

Overall, it has now been well established in several species that orexin deficiency results in an inability to maintain consolidated bouts of wakefulness and in inappropriate wake-to-REM sleep transitions. Although the $\mathrm{MCH}$ system has been involved in the regulation of REM sleep (Verret et al. 2003), the sleep phenotype of MCH and $\mathrm{MCH}$ receptor deletion has not yet been established.

A final neurotransmitter system important in sleep concerns GABA. GABA is the major inhibitory neurotransmitter acting on GABA-A and GABA-B receptors and is involved in both naturally occurring and benzodiazepineinduced sleep. Again, little genetic evidence is available, although point mutations in different GABA-A receptor subunits produce differential responses to sleep-inducing benzodiazepines (Tobler et al. 2001; Kopp et al. 2004). Overall, ligand or receptor knock out of the major neurotransmitter systems (if not lethal) have limited effects on sleep probably because of multiple neurotransmitter contributions and the compensatory effects of constitutional loss of function. Site- and time-specific gene deletion or knock down in these neurotransmitter pathways are necessary to delineate their respective contributions.

\section{MOLECULAR CORRELATES OF SLEEP NEED}

Sleep need builds during wakefulness and decreases during sleep. Therefore, genes for which the transcripts accumulate during wakefulness (and decrease during sleep) might be implicated in sleep regulation. Thus, as for circadian rhythms, sleep-wake regulation might also rely on an interplay of transcriptional regulators. Several aspects of sleep (e.g., the NREM-REM cycle) do not seem to be compatible with changes in gene expression because the time frame is too short. Changes in second messengers and posttranslational protein modifications could be considered instead (Schibler and Tafti 1999). Nevertheless, at least for sleep need, sleep-related genes may be induced and accumulate in a predictive manner. Different techniques have been used to isolate sleep- or wakefulness-specific transcripts (Tafti and Franken 2002). Here, we focus on the latest and most powerful approach, cDNA chip technology.

As opposed to the regulation of circadian rhythms for which a single brain structure seems to be responsible (i.e., the SCN), many brain regions have been implicated in the regulation of sleep, and for several, their role in sleep has not yet been well established. Some of these regions were 
briefly mentioned in the preceding paragraph, but in general, evidence for a specific role in sleep homeostasis is lacking with the exception, perhaps, of the locus coeruleus (Cirelli et al. 2005b) and the basal forebrain (Basheer et al. 2000). The EEG slow oscillations, the amplitude and prevalence of which are widely used as an EEG correlate of homeostatic sleep need (Borbely 1982), are generated by the interplay between the thalamus and the cortex. There is evidence that the hypothalamus, a highly specialized and complex brain region, is also involved in the homeostatic regulation of sleep (Saper et al. 2005).

Gene expression profiling has been attempted for several of these brain regions after spontaneous or enforced wakefulness in mice and rats. The first study (Terao et al. 2003) screened the expression on cDNA arrays of 1176 known genes in the cerebral cortex of $\mathrm{C} 57 \mathrm{BL} / 6 \mathrm{~J}$ mice after 6 hours of sleep deprivation and identified two gene categories for which mRNA expression was up-regulated. These include immediate-early genes such as Fos and several heat shock proteins such as Pdia4 (Erp-72) and Hspa5 (Grp78). Cirelli et al. (2004) screened 15,459 of 24,000 potential transcripts on rat RGU34A,B,C chips for differentially regulated transcripts by sleep and waking as well as by time of day (circadian) in the cortex and the cerebellum and found that approximately a similar number of transcripts $(5 \%)$ were affected by behavioral states and by time of day (day vs. night). In addition, they not only found that 490 transcripts were up-regulated by 8 hours of spontaneous or enforced wakefulness, but also that 261 transcripts were up-regulated after 8 hours of spontaneous sleep (Cirelli et al. 2004). The study confirmed the involvement of immediate-early and heat shock genes, and it also identified genes involved in synaptic plasticity, energy metabolism, and synaptic excitatory transmission being up-regulated during waking and genes involved in protein synthesis, lipid metabolism, and membrane trafficking being up-regulated during sleep (Cirelli et al. 2004).

Rest in the fruit fly Drosophila melanogaster shares all the important characteristics of sleep in mammals and birds, although they obviously lack the specific electrophysiological correlates that characterize sleep in mammals (Hendricks et al. 2000; Shaw et al. 2000). Of interest is the conservation of the homeostatic regulation of fly sleep as in other species. Therefore, it can be speculated that if sleep need is regulated at the transcriptional level, the same essential genes might also show changes in expression as a function of time spent in rest or activity. Accordingly, as in the rodent brain, rest deprivation and spontaneous wakefulness in the fly head induce up-regulation of genes belonging to specific categories. Wakefulness induces transcription factors, stress and immune response, and glutamatergic genes and genes involved in metabolism, whereas rest induces genes involved in lipid metabolism (Cirelli et al. 2005a), strongly suggesting a cross-species conservation of several molecular pathways involved in behavioral state control.

Another important question related to sleep function is the consequence of long-term sleep deprivation, which can result in death, for example, in rats after 2-3 weeks (Rechtschaffen and Bergmann 2002). Cirelli et al. (2006) addressed this question by sleep-depriving rats for either 8 hours or 1 week and profiling the expression of more than 24,000 transcripts in the cerebral cortex. Long-term sleep loss induced overexpression of genes involved in many inflammatory and stress response genes mainly in glial cells, suggesting a trend toward generalized brain pathology. In comparison, several synaptic plasticity genes were up-regulated only after short-term sleep deprivation (Cirelli et al. 2006).

The effects of a 6-hour sleep deprivation and 6-hour sleep deprivation followed by a 2-hour recovery sleep on gene expression were also investigated in the cortex, basal forebrain, and hypothalamus of rats and for 12 overexpressed genes replicated in the mouse (Terao et al. 2006). Although differences in the number of genes up- and down-regulated by sleep deprivation and recovery were found between the three brain regions, again, the most significant changes concerned immediate-early and heat shock protein genes in both species. Although different transcripts were found between the hypothalamus and cortex and basal forebrain, many genes changed expression in at least two of the three regions. In addition, several transcripts that were found to be up-regulated after sleep deprivation remained up-regulated following a 2-hour recovery sleep, suggesting a time course of dissipation not paralleling that of sleep need based on the dynamics of the amplitude and prevalence of EEG slow waves.

As opposed to the above-mentioned studies, two recent reports in flies and mice suggest that sleep deprivation results in a decrease in gene expression instead of an increase in gene expression (Zimmerman et al. 2006; Mackiewicz et al. 2007). In both studies, the expression data have been analyzed at different time points (with or without sleep deprivation) with a reference time point taken at the beginning of the consolidated rest or sleep period. In this analysis, circadian and sleepwake-dependent effects on gene expression are difficult to separate. Interestingly, Hspa5/Bip/Grp 78, which has been shown to invariably and most significantly increase expression after sleep deprivation in several species, was not detected by Zimmerman et al. in the flies (Zimmerman et al. 2006; Mackiewicz et al. 2007), although the same authors later claimed a major role for this heat shock protein in Drosophila sleep homeostasis (Naidoo et al. 2007).

The results summarized above raise several questions. Although brain structures thought to be implicated in sleep (cortex, hypothalamus) or not (cerebellum) have been investigated, it is not clear whether transcriptional changes occur in specific regions or in the whole brain (i.e., local vs. global). How specific transcriptional changes are to the brain has also not been determined because comparative analysis in other tissues is lacking. Even though time course analyses have been performed, systematic studies aiming at separating circadian and sleep-wake-dependent effects on gene transcription are also lacking. To overcome these limitations, we have performed a series of gene-profiling experiments in mice. We had already shown that sleep need varies with genetic background in mice (Franken et al. 2001); we therefore sleep-deprived three different mouse strains with differential recovery 
response to 6 hours of sleep deprivation. We also sampled the liver in the same animals as a reference peripheral organ for comparative transcriptome analysis with the whole brain. In both brain and liver, half of the differentially expressed transcripts were affected by genotype (S. Maret et al., in prep.). Transcriptional changes were much larger in the liver than in the brain, although, overall, few genes showed significant changes (less than 50 in the brain and 200 in the liver) after sleep deprivation. Most transcripts were up-regulated after sleep deprivation and belonged mainly to immediate-early, heat shock, and synaptic plasticity gene categories. However, by taking into account genetic background and tissue, very few genes showed consistent and brain-specific changes. Among these, the short splice variant of the Homerl gene (Homerla) showed the most significant increase in all three strains after sleep loss. We also performed another whole-brain transcriptome analysis by sleep-depriving the same three mouse strains for 6 hours at four time points around the clock. This experiment revealed that under baseline conditions (without sleep deprivation) approximately $8 \%$ (2032) of all microarray probe sets detected in the brain showed a significant time-of-day pattern of expression. However, under sleep deprivation conditions, only $1.5 \%$ (390 probe sets) remained cyclic, strongly suggesting that a large majority of cycling transcripts is modulated by behavioral states rather than being directly driven by the circadian clock. Among all rhythmic transcripts under baseline conditions, Homerla clearly showed the largest amplitude of variation. Homerla is an activity-induced gene involved in metabotropic glutamatergic neurotransmission and its up-regulation results in the buffering of intracellular calcium. These two experiments strongly suggested that Homer la represents a major molecular index of sleep need in the whole brain. Interestingly, Homerla maps in the middle of a region on mouse chromosome 13 that we had already identified by linkage analysis to be associated with sleep need (Franken et al. 2001). To further assess brain transcriptional changes induced by sleep deprivation, we generated a transgenic mouse model in which a Flag-tagged poly(A)-binding protein $(\mathrm{PABP})$ is expressed under the control of the Homer 1 promoter. Because PABP binds poly $(\mathrm{A})$ tails of mRNA for processing, immunoprecipitation of PABP-mRNA complexes by an antiepitope antibody results in enrichment and purification of mature mRNAs expressed in a cell-specific manner (Roy et al. 2002). Transcriptome analysis of Homer 1-expressing neurons after sleep deprivation revealed that in addition to Homerla, very few other genes are overexpressed by sleep loss. These include the activity-induced genes Fos-like 2 (Fosl2), Jonctaphilin 3 (Jph3), prostaglandin-endoperoxide synthase 2 (Ptgs 2$)$, and neuronal pentraxin 2 (Nptx2). Jph3 and Nptx2 are activity-induced through either ryanodine receptor-mediated intracellular calcium mobilization (Jph3) or activityinduced AMPA ( $\alpha$-amino-3-hydroxy-5-methyl-4-isoazole) receptor synaptic clustering (Nptx2). Among the very few down-regulated transcripts, another activityinduced gene, 4-nitrophenylphosphatase domain and nonneuronal SNAP25-like protein homolog 1 (Nipsnap1), was identified, suggesting that plasticity genes can be up- or down-regulated by sleep deprivation. On the basis of these findings, we have proposed that Homerla induction suggests a novel role for sleep in protecting and recovering from glutamatergic overstimulation imposed by wakefulness through transcriptional changes that ultimately regulate the intracellular calcium homeostasis.

\section{CONCLUSIONS}

As summarized here, the molecular basis of sleep remains poorly understood. Even at the very basic neurobiological level, no strong molecular evidence supports a specific role for any one of the major neurotransmission pathways. Whether sleep may be regulated at the transcriptional level remains unclear. Most studies indicate that immediate-early, heat shock, and synaptic plasticity genes are up-regulated by sleep loss. However, the specificity of these genes, except for Homerla, has not yet been established. In addition, induction of gene expression, even if specific to sleep loss, does not constitute proof of a functional role of this gene in sleep-wake regulation. Genes of all three categories are induced by spontaneous and induced neuronal activity, as well as in reaction to pathological conditions such as stroke, inflammation, or seizure. In accordance with the concept of the homeostatic regulation of sleep, the results of several gene-profiling experiments found increased transcription of a few functionally relevant genes during extended wakefulness, thus reflecting the molecular correlate of accumulated sleep need. Zimmerman et al. (2006) proposed an alternative hypothesis: A decrease rather than an increase in gene expression would result in reduction of the cellular processes that promote wakefulness. That experiments aimed at answering the same basic question and using the same techniques can arrive at such diverse results and interpretations is disquieting and calls for standardized designs and analyses.

As discussed above, the structural complexity of the brain and the multitude of signaling pathways involved in sleep, together with the lack of a "sleep homeostasis center" render the identification of molecular substrates of sleep highly complicated. In addition, at the mRNA level, a high complexity in mammals makes any detection of differentially expressed mRNA a tedious task, even by using microarray technology. Alternative possibilities are either to use the less complex model species such as the fruit fly or to use the more specific mRNA techniques such as the mRNA tagging that we have introduced. Serial analysis of gene expression (SAGE) and highly specific substractive hybridization techniques such as the selective amplification via biotin and restriction-mediated enrichment (SABRE) might overcome the limitations to detect low-abundance mRNAs. Finally, the analyses discussed here make inferences about the involvement of genes in sleep regulation based solely on the temporal and/or state-dependent changes in gene transcription while the dynamics of translation and posttranslational modification of gene products could importantly differ. As for the genome-wide expression profiling progress, differential proteomic approaches will depend on technological advances. Proteomic sleep studies have just begun 
to be performed (O'Hara et al. 2007). Finally, all gene expression experiments are correlative and gain- or lossof-function studies of identified genes are necessary to causally implicate any of the sleep target genes.

\section{ACKNOWLEDGMENTS}

This work is supported by the Swiss National Science Foundation and the State of Vaud, Switzerland.

\section{REFERENCES}

Basheer R., Porkka-Heiskanen T., Strecker R.E., Thakkar M.M., and McCarley R.W. 2000. Adenosine as a biological signal mediating sleepiness following prolonged wakefulness. Biol. Signals Recept. 9: 319.

Blanco-Centurion C., $\mathrm{Xu}$ M., Murillo-Rodriguez E., Gerashchenko D., Shiromani A.M., Salin-Pascual R.J., Hof P.R., and Shiromani P.J. 2006. Adenosine and sleep homeostasis in the basal forebrain. J. Neurosci. 26: 8092.

Borbely A.A. 1982. A two process model of sleep regulation. Hum. Neurobiol. 1: 195

Boutrel B., Franc B., Hen R., Hamon M., and Adrien J. 1999. Key role of 5-HT1B receptors in the regulation of paradoxical sleep as evidenced in 5-HT1B knock-out mice. J. Neurosci. 19: 3204 .

Boutrel B., Monaca C., Hen R., Hamon M., and Adrien J. 2002. Involvement of 5-HT1A receptors in homeostatic and stressinduced adaptive regulations of paradoxical sleep: Studies in 5-HT1A knock-out mice. J. Neurosci. 22: 4686.

Campbell S.S. and Tobler I. 1984. Animal sleep: A review of sleep duration across phylogeny. Neurosci. Biobehav. Rev. 8: 269.

Chemelli R.M., Willie J.T., Sinton C.M., Elmquist J.K., Scammell T., Lee C., Richardson J.A., Williams S.C., Xiong Y., Kisanuki Y., Fitch T.E., Nakazato M., Hammer R.E., Saper C.B., and Yanagisawa M. 1999. Narcolepsy in orexin knockout mice: Molecular genetics of sleep regulation. Cell 98: 437.

Cirelli C., Faraguna U., and Tononi G. 2006. Changes in brain gene expression after long-term sleep deprivation. $J$. Neurochem. 98: 1632.

Cirelli C., Gutierrez C.M., and Tononi G. 2004. Extensive and divergent effects of sleep and wakefulness on brain gene expression. Neuron 41: 35.

Cirelli C., LaVaute T.M., and Tononi G. 2005a. Sleep and wakefulness modulate gene expression in Drosophila. J. Neurochem. 94: 1411.

Cirelli C., Huber R., Gopalakrishnan A., Southard T.L., and Tononi G. 2005b. Locus ceruleus control of slow-wave homeostasis. J. Neurosci. 25: 4503.

Dauvilliers Y., Maret S., and Tafti M. 2005. Genetics of normal and pathological sleep in humans. Sleep Med. Rev. 9: 91.

Franken P., Chollet D., and Tafti M. 2001. The homeostatic regulation of sleep need is under genetic control. J. Neurosci. 21: 2610

Franken P., Thomason R., Heller H.C., and O'Hara B.F. 2007. A non-circadian role for clock-genes in sleep homeostasis: A strain comparison. BMC Neurosci. 8: 87.

Hara J., Beuckmann C.T., Nambu T., Willie J.T., Chemelli R.M., Sinton C.M., Sugiyama F., Yagami K., Goto K., Yanagisawa M., and Sakurai T. 2001. Genetic ablation of orexin neurons in mice results in narcolepsy, hypophagia, and obesity. Neuron 30: 345.

Hendricks J.C., Finn S.M., Panckeri K.A., Chavkin J., Williams J.A., Sehgal A., and Pack A.I. 2000. Rest in Drosophila is a sleep-like state. Neuron 25: 129.

Huang Z.L., Mochizuki T., Qu W.M., Hong Z.Y., Watanabe T., Urade Y., and Hayaishi O. 2006. Altered sleep-wake characteristics and lack of arousal response to $\mathrm{H} 3$ receptor antagonist in histamine $\mathrm{H} 1$ receptor knockout mice. Proc. Natl.
Acad. Sci. 103: 4687.

Huang Z.L., Qu W.M., Eguchi N., Chen J.F., Schwarzschild M.A., Fredholm B.B., Urade Y., and Hayaishi O. 2005. Adenosine A2A, but not A1, receptors mediate the arousal effect of caffeine. Nat. Neurosci. 8: 858.

Hunsley M.S. and Palmiter R.D. 2003. Norepinephrine-deficient mice exhibit normal sleep-wake states but have shorter sleep latency after mild stress and low doses of amphetamine. Sleep 26: 521 .

Kopp C., Rudolph U., Low K., and Tobler I. 2004. Modulation of rhythmic brain activity by diazepam: GABA(A) receptor subtype and state specificity. Proc. Natl. Acad. Sci. 101: 3674.

Kume K., Kume S., Park S.K., Hirsh J., and Jackson F.R. 2005. Dopamine is a regulator of arousal in the fruit fly. J. Neurosci. 25: 7377.

Lena C., Popa D., Grailhe R., Escourrou P., Changeux J.P., and Adrien J. 2004. Beta2-containing nicotinic receptors contribute to the organization of sleep and regulate putative micro-arousals in mice. J. Neurosci. 24: 5711.

Lin L., Faraco J., Li R., Kadotani H., Rogers W., Lin X., Qiu X., de Jong P.J., Nishino S., and Mignot E. 1999. The sleep disorder canine narcolepsy is caused by a mutation in the hypocretin (orexin) receptor 2 gene. Cell 98: 365.

Mackiewicz M., Shockley K.R., Romer M.A., Galante R.J., Zimmerman J.E., Naidoo N., Baldwin D.A., Jensen S.T., Churchill G.A., and Pack A.I. 2007. Macromolecule biosynthesis-A key function of sleep. Physiol. Genomics (in press).

Maret S., Franken P., Dauvilliers Y., Ghyselinck N.B., Chambon P., and Tafti M. 2005. Retinoic acid signaling affects cortical synchrony during sleep. Science 310: 111.

McCarley R.W. 2007. Neurobiology of REM and NREM sleep. Sleep Med. 8: 302.

Modirrousta M., Mainville L., and Jones B.E. 2005. Orexin and $\mathrm{MCH}$ neurons express c-Fos differently after sleep deprivation vs. recovery and bear different adrenergic receptors. Eur. J. Neurosci. 21: 2807.

Naidoo N., Casiano V., Cater J., Zimmerman J., and Pack A.I. 2007. A role for the molecular chaperone protein BiP/GRP78 in Drosophila sleep homeostasis. Sleep 30: 557.

Noor Alam M.D., Szymusiak R., and McGinty D. 2006. Adenosinergic regulation of sleep: Multiple sites of action in the brain. Sleep 29: 1384.

O'Hara B.F., Ding J., Bernat R.L., and Franken P. 2007. Genomic and proteomic approaches towards an understanding of sleep. CNS Neurol. Disord. Drug Targets 6: 71.

Ouyang M., Hellman K., Abel T., and Thomas S.A. 2004. Adrenergic signaling plays a critical role in the maintenance of waking and in the regulation of REM sleep. $J$. Neurophysiol. 92: 2071.

Parmentier R., Ohtsu H., Djebbara-Hannas Z., Valatx J.L., Watanabe T., and Lin J.S. 2002. Anatomical, physiological, and pharmacological characteristics of histidine decarboxylase knock-out mice: Evidence for the role of brain histamine in behavioral and sleep-wake control. J. Neurosci. 22: 7695.

Parmentier R., Anaclet C., Guhennec C., Brousseau E., Bricout D., Giboulot T., Bozyczko-Coyne D., Spiegel K., Ohtsu H., Williams M., and Lin J.S. 2007. The brain H3-receptor as a novel therapeutic target for vigilance and sleep-wake disorders. Biochem. Pharmacol. 73: 1157.

Rechtschaffen A. and Bergmann B.M. 2002. Sleep deprivation in the rat: An update of the 1989 paper. Sleep 25: 18.

Retey J.V., Adam M., Khatami R., Luhmann U.F., Jung H.H., Berger W., and Landolt H.P. 2007. A genetic variation in the adenosine A2A receptor gene (ADORA2A) contributes to individual sensitivity to caffeine effects on sleep. Clin. Pharmacol. Ther. 81: 692.

Retey J.V., Adam M., Honegger E., Khatami R., Luhmann U.F., Jung H.H., Berger W., and Landolt H.P. 2005. A functional genetic variation of adenosine deaminase affects the duration and intensity of deep sleep in humans. Proc. Natl. Acad. Sci. 102: 15676.

Roy P.J., Stuart J.M., Lund J., and Kim S.K. 2002. Chromosomal clustering of muscle-expressed genes in Caenorhabditis elegans. Nature 418: 975. 
Saper C.B., Scammell T.E., and Lu J. 2005. Hypothalamic regulation of sleep and circadian rhythms. Nature 437: 1257.

Schibler U. and Tafti M. 1999. Molecular approaches towards the isolation of sleep-related genes. J. Sleep. Res. (suppl. 1) 8: 1 .

Shaw P.J., Cirelli C., Greenspan R.J., and Tononi G. 2000. Correlates of sleep and waking in Drosophila melanogaster. Science 287: 1834.

Stefansson H., Rye D.B., Hicks A., Petursson H., Ingason A., Thorgeirsson T.E., Palsson S., Sigmundsson T., Sigurdsson A.P., Eiriksdottir I., Soebech E., Bliwise D., Beck J.M., Rosen A., Waddy S., Trotti L.M., Iranzo A., Thambisetty M., Hardarson G.A., Kristjansson K., Gudmundsson L.J., Thorsteinsdottir U., Kong A., Gulcher J.R., Gudbjartsson D., and Stefansson K. 2007. A genetic risk factor for periodic limb movements in sleep. N. Engl. J. Med. 357: 639.

Tafti M. and Franken P. 2002. Invited review: Genetic dissection of sleep. J. Appl. Physiol. 92: 1339.

Tafti M., Dauvilliers Y., and Overeem S. 2007. Narcolepsy and familial advanced sleep-phase syndrome: Molecular genetics of sleep disorders. Curr. Opin. Genet. Dev. 17: 222.

Tafti M., Maret S., and Dauvilliers Y. 2005. Genes for normal sleep and sleep disorders. Ann. Med. 37: 580.

Tafti M., Chollet D., Valatx J.L., and Franken P. 1999. Quantitative trait loci approach to the genetics of sleep in recombinant inbred mice. J. Sleep Res. (suppl. 1) 8: 37.

Tafti M., Petit B., Chollet D., Neidhart E., de Bilbao F., Kiss J.Z., Wood P.A., and Franken P. 2003. Deficiency in shortchain fatty acid beta-oxidation affects theta oscillations during sleep. Nat. Genet. 34: 320.

Terao A., Wisor J.P., Peyron C., Apte-Deshpande A., Wurts S.W., Edgar D.M., and Kilduff T.S. 2006. Gene expression in the rat brain during sleep deprivation and recovery sleep: An Affymetrix GeneChip study. Neuroscience 137: 593.

Terao A., Steininger T.L., Hyder K., Apte-Deshpande A., Ding J., Rishipathak D., Davis R.W., Heller H.C., and Kilduff T.S. 2003. Differential increase in the expression of heat shock protein family members during sleep deprivation and during sleep. Neuroscience 116: 187.

Tobler I., Kopp C., Deboer T., and Rudolph U. 2001. Diazepaminduced changes in sleep: Role of the alpha 1 GABA(A) receptor subtype. Proc. Natl. Acad. Sci. 98: 6464.
Trachsel L., Edgar D.M., Seidel W.F., Heller H.C., and Dement W.C. 1992. Sleep homeostasis in suprachiasmatic nucleilesioned rats: Effects of sleep deprivation and triazolam administration. Brain Res. 589: 253.

Urade Y., Eguchi N., Qu W.M., Sakata M., Huang Z.L., Chen J.F., Schwarzschild M.A., Fink J.S., and Hayaishi O. 2003. Sleep regulation in adenosine A2A receptor-deficient mice. Neurology 61: S94.

Verret L., Goutagny R., Fort P., Cagnon L., Salvert D., Leger L., Boissard R., Salin P., Peyron C., and Luppi P.H. 2003. A role of melanin-concentrating hormone producing neurons in the central regulation of paradoxical sleep. BMC Neurosci. 4: 19.

Wess J. 2004. Muscarinic acetylcholine receptor knockout mice: Novel phenotypes and clinical implications. Annu. Rev. Pharmacol. Toxicol. 44: 423.

Willie J.T., Chemelli R.M., Sinton C.M., Tokita S., Williams S.C., Kisanuki Y.Y., Marcus J.N., Lee C., Elmquist J.K., Kohlmeier K.A., Leonard C.S., Richardson J.A., Hammer R.E., and Yanagisawa M. 2003. Distinct narcolepsy syndromes in Orexin receptor-2 and Orexin null mice: Molecular genetic dissection of Non-REM and REM sleep regulatory processes. Neuron 38: 715 .

Winkelmann J., Schormair B., Lichtner P., Ripke S., Xiong L., Jalilzadeh S., Fulda S., Putz B., Eckstein G., Hauk S., Trenkwalder C., Zimprich A., Stiasny-Kolster K., Oertel W., Bachmann C.G., Paulus W., Peglau I., Eisensehr I., Montplaisir J., Turecki G., Rouleau G., Gieger C., Illig T., Wichmann H.E., Holsboer F., Muller-Myhsok B., and Meitinger T. 2007. Genome-wide association study of restless legs syndrome identifies common variants in three genomic regions. Nat. Genet. 39: 1000.

Wisor J.P., Nishino S., Sora I., Uhl G.H., Mignot E., and Edgar D.M. 2001. Dopaminergic role in stimulant-induced wakefulness. J. Neurosci. 21: 1787 .

Wisor J.P., Wurts S.W., Hall F.S., Lesch K.P., Murphy D.L., Uhl G.R., and Edgar D.M. 2003. Altered rapid eye movement sleep timing in serotonin transporter knockout mice. Neuroreport 14: 233.

Zimmerman J.E., Rizzo W., Shockley K.R., Raizen D.M., Naidoo N., Mackiewicz M., Churchill G.A., and Pack A.I. 2006. Multiple mechanisms limit the duration of wakefulness in Drosophila brain. Physiol. Genomics 27: 337. 


\section{$8_{\mathrm{CSH}}^{\infty} \mathrm{C}$ Cold Spring Harbor Symposia SYMPOSIA}

\section{Molecular Analysis of Sleep}

M. Tafti and P. Franken

Cold Spring Harb Symp Quant Biol 2007 72: 573-578

Access the most recent version at doi:10.1101/sqb.2007.72.054

References This article cites 57 articles, 16 of which can be accessed free at: http://symposium.cshlp.org/content/72/573.full.html\#ref-list-1

\section{License}

Email Alerting

Receive free email alerts when new articles cite this article - sign up in the box at the Service top right corner of the article or click here.

To subscribe to Cold Spring Harbor Symposia on Quantitative Biology go to: http://symposium.cshlp.org/subscriptions 